\title{
Variation near the Region of the Lipoprotein Lipase Gene and Hypertension or Blood Pressure Levels in Chinese
}

\author{
Wenjie $\mathrm{YANG}^{* 1,2}$, Jianfeng $\mathrm{HUANG}^{* 1}$, Dongliang GE ${ }^{* 2}$, Cailiang YAO ${ }^{* 4}$, Xiufang DUAN ${ }^{* 1}$, \\ Wenqi GAN ${ }^{* 1}$, Guangyong HUANG ${ }^{* 1}$, Jiangong $\mathrm{ZHAO}^{* 1}$, Rutai HUI ${ }^{* 3}$, Yan SHEN *2, \\ Boqin QIANG ${ }^{* 2}$, and Dongfeng GU*1,2
}

\begin{abstract}
Essential hypertension (EH) is a common late-onset disease that exhibits complex genetic heterogeneity. Human lipoprotein lipase (LPL) is a rate-limiting enzyme that regulates the catabolism of triglycerides (TG) and chylomicrons (CM). Since dyslipidemia is a common finding in hypertensive patients, the LPL gene is a logical candidate gene that could contribute to the development of hypertension. Using linkage analysis in 148 Chinese hypertensive families, we identified a region of linkage with systolic blood pressure (SBP) and diastolic blood pressure (DBP) that consisted of a 10.6-cM interval defined by markers D8S1145, D8S261, and D8S282 on chromosome 8, which maps between 31 to $41.6 \mathrm{cM}$ from the $8 \mathrm{p}$-telomere contained LPL gene, with statistically significant $p$ values for the marker D8S261 ( $p=0.0021$ for SBP, and $p=0.0395$ for DBP). In the qualitative-trait linkage analysis, evidence for linkage between the marker D8S1145 and EH was found $(p=0.0286)$. The transmission/disequilibrium test (TDT/S-TDT) also supported a significant linkagedisequilibrium of the allele 3 of D8S261 with EH $\left(X^{2}=8.643, p<0.01\right)$. Furthermore, the marker neurofilament light polypeptide (NEFL) (11 cM centromeric to the LPL gene) appeared to be in linkage with SBP and DBP ( $p=\mathbf{0 . 0 3 2 9}$ for SBP; $p=\mathbf{0 . 0 3 1 9}$ for DBP). Additionally, two flanking markers for LPL, D8S511 (9.5 cM telomeric to the LPL gene) and D8S560 (3.2 cM centromeric to the LPL gene), also showed significant linkage with EH ( $p=0.0036$ for D8S511; $p=0.0115$ for D8S560). Previous knowledge about the physiological involvement of LPL in blood pressure regulation and the present findings of variation near the LPL gene support the proposition that a region near the LPL gene or the LPL gene itself might contribute to the individual blood pressure variation in Chinese. (Hypertens Res 2003; 26: 459-464)
\end{abstract}

Key Words: lipoprotein lipase, hypertension, essential, family, blood pressure level

\section{Introduction}

Essential hypertension (EH) is a major risk factor for cardio- vascular, cerebrovascular, and renal diseases. It is a common late-onset disease that exhibits complex genetic heterogeneity as a result of the interplay among genetic and environmental factors. Blood pressure (BP) is a complex trait regu-

From ${ }^{* 1}$ the Division of Population Genetics, Cardiovascular Institute and Fu Wai Hospital, Chinese Academy of Medical Sciences and Peking Union Medical College, Beijing, P.R.China, ${ }^{* 2}$ National Human Genome Center at Beijing, Beijing, P.R.China, ${ }^{* 3}$ Sino-German Molecular Medicine Laboratory, Cardiovascular Institute, Fu Wai Hospital, Beijing, P.R.China, and ${ }^{* 4}$ Nanjing Medical University School of Public Health, Nanjing, China. This work was funded by Grants-in-Aid from the National High Technology Research and Development Program from the Ministry of Science and Technology of the People's Republic of China (Nos. 2001AA227081 and Z19-01-03-01) and from the Biomedical Project from the Council of Science and Technology, Beijing (No. H010210370113). Most of the lab work was completed at the Chinese National Human Genome Center, Beijing. Some of the results of the sib pair linkage analysis were obtained by use of the program package S.A.G.E., which is supported by a US Public Health Service Resource Grant (RR03655) from the National Center for Research Resources, and some results were calculated from TDT/S-TDT program.

Address for Reprints: Dongfeng Gu, M.D., M.S., Division of Population Genetics, Cardiovascular Institute, Fu Wai Hospital, Chinese Academy of Medical Sciences and Peking Union Medical College, 167 Beilishi Road, Beijing 100037, P.R.China. E-mail: gudf@yahoo.com

Received November 11, 2002; Accepted in revised form January 29, 2003. 
lated by the interaction among multiple physiologic regulatory systems and likely involving numerous genes (1). EH is frequently associated with serum lipid abnormalities, and has been found to occur more often than expected in families with familial combined hyperlipidemia (2). This suggests that there may be common underlying genetic determinants between BP regulation and lipid metabolism. Human lipoprotein lipase (LPL) plays a major role in the determination of the plasma lipid and lipoprotein profile, and is a ratelimiting enzyme responsible for the hydrolysis of triglycerides (TG) in chylomicrons (CM) and very-low-density lipoprotein (VLDL) (3). The LPL gene may be one of these genetic determinants.

Extensive researches have been directed at genetic variants of the LPL gene in patients with dyslipidemia in order to elucidate predisposition to coronary heart disease (CAD), myocardial infarction (MI), cerebral infarction, or diabetes mellitus (4-6). To date, only a few studies have explored the relation between the genetic variants near or in the LPL gene and BP variation. Positive linkage or association has been described in some studies, which indicate that the LPL gene may be an important candidate for affecting the risk of $\mathrm{EH}$ or $\mathrm{BP}$ variation $(1,2,7,8)$.

This study selected highly polymorphic microsatellite markers in a region near the LPL gene in a large sample of Chinese hypertensive families, and used the sib pair linkage method (S.A.G.E./SIBPAL 2) and the transmission/disequilibrium test (TDT/S-TDT) to further investigate the linkage and association between BP variation and this region near the LPL gene.

\section{Methods}

\section{Study Population}

All 799 individuals were members of 148 hypertensive nuclear families who were determined to have at least two affected siblings each. Hypertensive nuclear families were initially screened by local medical doctors, who had received rigorous training in epidemiology and BP measurement and who had passed an appropriate proficiency test. To be eligible for our study, an individual belonging to a sib pair in one of the nuclear families had to meet the following criteria: resting-sitting systolic blood pressure $(\mathrm{SBP}) \geq 140 \mathrm{mmHg}$ and/or diastolic blood pressure (DBP) $\geq 90 \mathrm{mmHg}$ on three different occasions or use of antihypertensive medication (patients who had taken medication over the previous 2 weeks and refused to withdraw from medication were excluded); no evidence of secondary hypertension in family members; age greater than 15 years; and hypertension in one or both of the parents. All participants were of Han ethnicity, which accounts for about $96 \%$ of the total population in the mainland of China, and currently residing in suburbs of Beijing (Fangshan and Shijingshan Districts), in Jiangsu Province (Changshu, Taixing, and Zhangjiagang Districts), or in Shanxi Province (Hanzhong City).

Once families were identified, epidemiologists and cardiologists from Fu Wai Hospital went to the local site to confirm the family eligibility. After positive confirmation, a formal study was conducted in the local hospital. Trained interviewers using standard questionnaires collected information on demographic characteristics, history of cardiovascular disease, lifestyle factors, and family history of hypertension. Anthropometric measurements, including height and weight, and an electrocardiogram were taken according to standard protocols. BP measurements were obtained by experienced doctors or nurses using a standard mercury sphygmomanometer with appropriately sized cuffs on the subject's right arm after a 10-min rest. Three measurements were taken with an interval of at least $30 \mathrm{~s}$ between readings. The study protocol was approved by the local research ethics committee of the Cardiovascular Institute and Fu Wai Hospital, Chinese Academy of Medical Sciences and Peking Union Medical College. Informed consent was obtained from all study subjects.

\section{Genotyping}

Genomic DNA was obtained from peripheral blood leukocytes by phenol/chloroform extraction and stored at $-20^{\circ} \mathrm{C}$. Fluorescent-based genotyping was carried out with seven highly polymorphic microsatellite markers: D8S511, D8S1145, D8S261, D8S258, D8S282, and D8S560, and the neurofilament light polypeptide (NEFL; a dinucleotide-repeat in the NEFL gene). The primer sequences were acquired from the Genome Database (http://gdbwww.gdb.org/), and the forward primer was labeled with fluorescence at the 5 end. Touch-down polymerase chain reaction (TD-PCR) was performed in thermocyclers of a Perkim Geneamp 9700 (Applied Biosystems, Foster City, USA) in a $5 \mu$ l reaction volume, which included $10 \mathrm{mmol} / \mathrm{l}$ Tris- $\mathrm{HCl}, \mathrm{pH} 8.3$, $50 \mathrm{mmol} / \mathrm{l} \mathrm{KCl}, 2.5 \mathrm{mmol} / 1 \mathrm{MgCl}_{2}, 2 \mathrm{mmol} / \mathrm{l} \mathrm{dNTPs}, 0.2 \mathrm{U}$ AmpliTaq Gold polymerase, $5 \mu \mathrm{mol} / \mathrm{l}$ of each primer and $50 \mathrm{ng}$ genomic DNA in 96-well plates. The amplifications involved initial denaturation for $10 \mathrm{~min}$ at $95^{\circ} \mathrm{C}$, followed by 42 cycles of denaturation for $30 \mathrm{~s}$ at $94^{\circ} \mathrm{C}$, annealing for $40 \mathrm{~s}$ at $56^{\circ} \mathrm{C}$, and extension for $60 \mathrm{~s}$ at $72^{\circ} \mathrm{C}$, with the exception of the first 17 cycles, in which the annealing temperatures decreased from $63^{\circ} \mathrm{C}$ to $56^{\circ} \mathrm{C}$ by $0.5^{\circ} \mathrm{C}$ per cycle. At the end of the amplifications, an extension reaction was performed at $72^{\circ} \mathrm{C}$ for $10 \mathrm{~min}$.

PCR products were mixed with the DNA size standard (Genescan Rox-HD400; Applied Biosystems Inc.), dextran blue dye (loading buffer), and formamide. The electrophoresis was carried out in $1 \times \mathrm{TBE}$ at $51^{\circ} \mathrm{C}, 3 \mathrm{kV}$ for $2.5 \mathrm{~h}$ using an automatic DNA sequencer (ABI 377; Applied Biosystems Inc.). The size of microsatellite DNA fragments was measured using Genescan 3.1 software (Applied Biosystems Inc.). The alleles were further defined using Genotype 2.1 software (Applied Biosystems Inc.). Genotypes of pedi- 
Table 1. Structure and Number of Sibs in Confirmed Hypertensive Families

\begin{tabular}{|c|c|c|c|c|}
\hline \multirow{2}{*}{ Parents } & \multicolumn{3}{|c|}{ No. of sibs per nuclear family } & \multirow{2}{*}{$\begin{array}{l}\text { Total } \\
\text { families }\end{array}$} \\
\hline & 2 & 3 & $\geq 4$ & \\
\hline Both affected & 7 & 17 & 18 & 42 \\
\hline One affected & 33 & 27 & 46 & 106 \\
\hline
\end{tabular}

gree members in 148 families were verified for Mendelian segregation. The entire allelotyping procedure was verified by using genomic DNA from CEPH families 1347-02.

\section{Statistical Analysis}

Qualitative-trait and quantitative-trait linkage analyses were performed using the SIBPAL 2 program of the S.A.G.E. package (9).

The TDT is a test of association in the presence of linkage. Besides conventional TDT, an extended TDT (S-TDT and combined $Z$ score) was also performed. Since EH is a late-onset disease, sometimes the data from parents are difficult to obtain. In cases in which the genotype for one parent is missing, a bias can arise in the TDT. S-TDT, on the other hand, compares the marker genotypes in affected and unaffected offspring, but without the potential bias of TDT. Therefore, a combined $Z$ score was obtained by combining information from TDT and S-TDT and making the Bonferroni's correction (10).

\section{Results}

\section{Study Sample}

The structures of sibs in the 148 hypertensive families are shown in Table 1 . Clinical characteristics of all subjects by hypertension status are shown in Table 2 . There were statistically significant differences in age, SBP, DBP, and body mass index (BMI) between hypertensives and normotensives.

\section{Sib Pair Linkage Analysis}

In the 148 sibships, which together represented 500 hypertensive patients (328 affected sib pairs), we conducted sib pair quantitative and qualitative-trait linkage analysis using the program S.A.G.E./SIBPAL 2, and identified a region of linkage with SBP and DBP to a 10.6-cM interval defined by markers D8S1145, D8S261, and D8S282 on chromosome 8 (see Table 3), which maps between 31 to $41.6 \mathrm{cM}$ from the 8 p-telomere contained LPL gene, with statistically significant $p$ values for the marker D8S261 ( $p=0.0021$ for SBP; $p=0.0395$ for DBP). In the qualitative-trait linkage analysis, evidence for linkage between the marker D8S1145 and EH was found $(p=0.0286)$. Three additional flanking markers of the LPL gene, which map from 29.5 to $50 \mathrm{cM}$, also yielded some positive linkage signals. In quantitative-trait linkage analysis, the marker NEFL (11 cM centromeric to the LPL gene) appeared to be in linkage with SBP and DBP ( $p=0.0329$ for SBP; $p=0.0319$ for DBP). In qualitativetrait linkage analysis, a significant linkage was observed between either of two markers, D8S511 $(9.5 \mathrm{cM}$ telomeric to the LPL gene) and D8S560 (3.2 cM centromeric to the LPL gene), and $\mathrm{EH}(p=0.0036$ for D8S511; $p=0.0115$ for D8S560). More statistically significant $p$ values were obtained for the markers D8S261 and D8S1145 by conducting multipoint linkage analyses of seven markers: D8S511, D8S1145, D8S261, D8S258, D8S282, D8S560, and NEFL (see Table 4). Figure 1 graphs the $p$ values for the association between SBP or DBP and each of the seven microsatellite markers, which are listed in the order of their proximity to the $8 \mathrm{p}$-telomere.

\section{TDT/S-TDT Analysis}

TDT/S-TDT analysis was performed after we had detected some positive linkage signals at the markers D8S511, D8S1145, D8S261, D8S560, and NEFL. We did not detect statistically significant excess transmission of any allele for the markers D8S511, D8S1145, D8S560, or NEFL with EH. However, a significant association between the marker D8S261 and hypertension was found. Allele 3 of the marker D8S261 showed significant transmission-disequilibrium with EH in the traditional TDT and S-TDT tests $\left(\chi^{2}=8.643\right.$ and $p<0.01$, and $Z^{\prime}=2.408$ and $p<0.05$, respectively) and Bonferroni's correction performance $\left(Z^{\prime}=3.517, p<0.01\right)$.

\section{Discussion}

A logical approach to dissecting the genetic determinants of BP is to examine the genes that encode products with known biological effects on BP regulation (11). To date, genetic studies have identified a substantial number of genes in which variants impart effects on $\mathrm{BP}$, providing new insight into the causes of hypertension. On the other hand, genetic studies in different populations have been fairly disappointing, since they have failed to identify any variants that account for substantial effects, although reproduction of the findings in different ethnic populations is generally considered to be important (12-14). In reality, polymorphisms of a certain gene could be associated with a phenotype in one ethnic population but not in another, such that different genes may predispose to the phenotype of hypertension in different populations (13). The above findings suggest that there are no major loci that make a major contribution to the variation in BP among different populations, abut rather many genes which contribute very small effects to BP.

$\mathrm{BP}$ is maintained by a well-characterized, complex network of integrated and redundant systems that include renal, neuronal, endocrine, glucose and lipid metabolism, and vas- 
Table 2. Descriptive Statistics in Hypertensive Families

\begin{tabular}{lccccccc}
\hline \multirow{2}{*}{ Group } & \multicolumn{2}{c}{ No. of individuals } & \multirow{2}{*}{ Age (years) } & \multirow{2}{*}{ BMI $\left(\mathrm{kg} / \mathrm{m}^{2}\right)$} & \multirow{2}{*}{$\mathrm{SBP}(\mathrm{mmHg})$} & $\mathrm{DBP}(\mathrm{mmHg})$ \\
\cline { 2 - 3 } & Male & Female & & & & & \\
\hline Normal & 185 & 114 & & $46.82 \pm 12.74$ & $24.74 \pm 3.31$ & $122.79 \pm 18.44$ & $78.72 \pm 11.34$ \\
Hypertension & 282 & 218 & & $54.83 \pm 13.91^{*}$ & $25.31 \pm 3.75^{\#}$ & $152.32 \pm 22.66^{*}$ & $92.74 \pm 12.61^{*}$ \\
\hline
\end{tabular}

${ }^{\#} p<0.05,{ }^{*} p<0.01$. BMI, body mass index; SBP, systolic blood pressure; DBP, diastolic blood pressure.

Table 3. Quantitative-Trait Linkage Analysis of Chromosome 8 for SBP and DBP among 520 Sib Pairs

\begin{tabular}{|c|c|c|c|c|c|c|}
\hline \multirow{2}{*}{ Marker } & \multicolumn{3}{|c|}{ SBP } & \multicolumn{3}{|c|}{ DBP } \\
\hline & $\beta$ & $\mathrm{SE}$ & $p$ value & $\beta$ & $\mathrm{SE}$ & $p$ value \\
\hline D8S261 & 0.6688 & 0.2328 & $0.0021^{* *}$ & 0.4792 & 0.2723 & 0.0395 \\
\hline D8S282 & 0.0170 & 0.2365 & 0.4714 & 0.0471 & 0.2923 & 0.4360 \\
\hline D8S1145 & 0.2230 & 0.2072 & 0.1411 & 0.1988 & 0.2476 & 0.2112 \\
\hline
\end{tabular}

${ }^{*} p<0.05,{ }^{* *} p<0.01$. SBP, systolic blood pressure; DBP, diastolic blood pressure.

Table 4. Evidence for Linkage of SBP, DBP, and EH to the LPL Gene Region on Chromosome 8

\begin{tabular}{|c|c|c|c|c|c|c|c|c|c|c|c|}
\hline \multirow{2}{*}{ Markers } & \multirow{2}{*}{$\begin{array}{l}\text { Heterozy- } \\
\text { gosity }\end{array}$} & \multirow{2}{*}{$\begin{array}{l}\text { Genetic distance } \\
\text { from the } 8 \mathrm{p}- \\
\text { telomere }(\mathrm{cM})\end{array}$} & \multicolumn{3}{|c|}{ SBP } & \multicolumn{3}{|c|}{ DBP } & \multicolumn{3}{|c|}{$\mathrm{EH}$} \\
\hline & & & $\beta$ & SE & $p$ value & $\beta$ & SE & $p$ value & $\beta$ & SE & $p$ value \\
\hline D8S511 & 0.67 & 29.5 & 0.1794 & 0.1963 & 0.1806 & -0.0878 & 0.2333 & 0.6467 & 0.0826 & 0.0307 & $0.0036^{* *}$ \\
\hline D8S1145 & 0.73 & 31.0 & 0.3495 & 0.1837 & $0.0288^{*}$ & 0.2382 & 0.2187 & 0.1382 & 0.0674 & 0.0288 & $0.0097^{* *}$ \\
\hline D8S261 & 0.78 & 35.8 & 0.7331 & 0.2072 & $0.0002^{* *}$ & 0.5420 & 0.2477 & $0.0145^{*}$ & 0.0506 & 0.0335 & 0.0659 \\
\hline D8S258 & 0.70 & 40.3 & 0.2248 & 0.1766 & 0.1017 & 0.2583 & 0.2097 & 0.1092 & 0.0019 & 0.0274 & 0.4727 \\
\hline D8S282 & 0.71 & 41.6 & 0.0481 & 0.2094 & 0.4092 & 0.0411 & 0.2489 & 0.4345 & 0.0197 & 0.0337 & 0.2796 \\
\hline D8S560 & 0.75 & 42.2 & 0.0556 & 0.1652 & 0.3682 & 0.1804 & 0.1961 & 0.1789 & 0.0594 & 0.0261 & $0.0115^{*}$ \\
\hline NEFL & 0.81 & 50.0 & 0.3202 & 0.1738 & $0.0329^{*}$ & 0.3834 & 0.2065 & $0.0319^{*}$ & 0.0355 & 0.0279 & 0.1018 \\
\hline
\end{tabular}

${ }^{*} p<0.05,{ }^{* *} p<0.01$. SBP, systolic blood pressure; DBP, diastolic blood pressure; EH, essential hypertension; LPL, lipoprotein lipase; NEFL, neurofilament light polypeptide.

cular mechanisms (15). Lipid metabolism is considered to be an important pathway of BP control (2). Although the way in which LPL is involved in the development of hypertension is not apparent, hypertension has been found to occur more often than expected in families with familial combined hyperlipidemia. Membrane ion transport, which has been related to hypertension, can be altered by lipid abnormalities and could have some involvement in the mechanisms that relate high triglyceride levels and hypertension (2). Another possible pathophysiological mechanism would involve the ability of elevated triglyceride to induce hyperinsulinemia, which could lead to hypertension through its effects on renal hemodynamics, sodium reabsorption and retention, and vascular hypertrophy (16).

In a quantitative sib pair linkage analysis in a Taiwanese population, BP was shown to be strongly linked to the LPL gene (7). Another genetic linkage study of young-onset hypertension in Taiwan suggested positive linkage between the marker D8S1145 near the LPL gene and hypertension (2). Zhu et al. similarly showed that the LPL gene could be linked to $\mathrm{EH}$ in 95 Chinese families (8). However, in their study on a Caucasian population in the United States, Hunt et al. found no relation between the LPL gene and high BP (17). There were several important differences between our study and that of $\mathrm{Wu}$ et al. (7). There was an apparent discrepancy in phenotype selection (their study utilized 48 Taiwanese families with a clinical phenotype of non-insulindependent diabetes mellitus (NIDDM)). In addition, our sample size was larger than theirs, and environmental differences may also have played a role. As a result, we found evidence of linkage between several markers and SBP, DBP, and hypertension, while only SBP was linked to markers in the Taiwanese study.

In an effort to identify variation near the region of the LPL gene contributing to the linkage or associated with $\mathrm{EH}$ or $\mathrm{BP}$, we examined markers near the LPL gene in a large sample of individuals residing in rural areas in China. A total of 148 sibships representing 328 affected sib pairs were studied. In a 20-cM region flanking the LPL gene, five high polymorphic markers (D8S511, D8S1145, D8S261, D8S560 and NEFL) all provided evidence of linkage or association with SBP, DBP, and hypertension. 


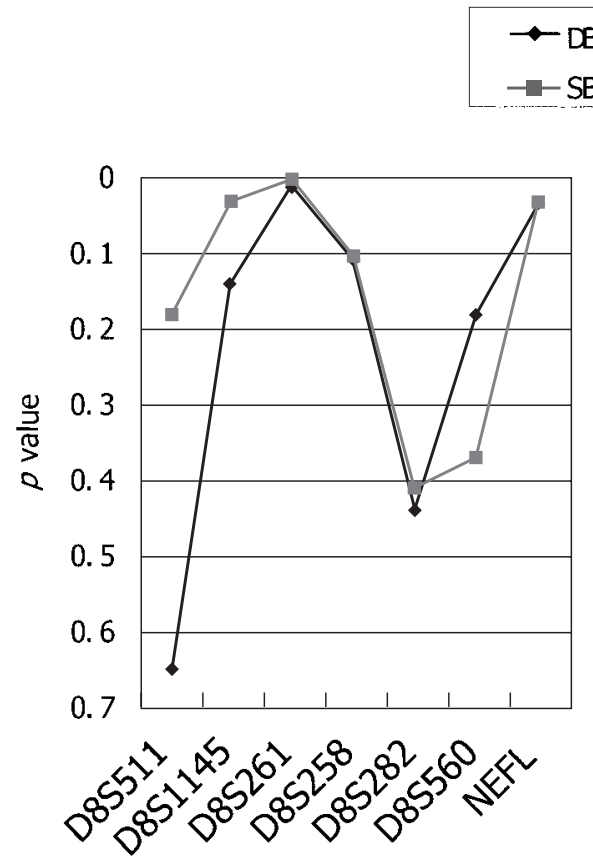

Fig. 1. $P$ values of $S B P$ and $D B P$ from the sib pair linkage analysis with seven markers.

Results from studies on Chinese populations, including ours, have suggested that variation near the region of the LPL gene is almost certain to play a role in BP variation. The genes contributing to BP variance will be pinpointed from BP quantitative trait loci (QTLs). The location of the QTL itself can potentially be refined by genotyping additional markers and linkage analysis (18). The human LPL gene has been localized to chromosome 8p22 (19). In this region, the marker D8S261, mapped at $3.2 \mathrm{cM}$ from the telomeric of chromosome 8 to the LPL gene, showed evidence of linkage with SBP and DBP $(p=0.0021$ for SBP; $p=0.0395$ for $\mathrm{DBP})$. Extending this region in the direction of the centromere, the marker NEFL, a dinucleotide repeat in the NEFL gene (11 cM centromeric to the LPL gene), was also found to be in linkage with SBP and DBP ( $p=0.0329$ for SBP; $p=0.0319$ for DBP). It has been well established that mutations in the NEFL gene are associated with breast cancer and Charcot-Marie-Tooth disease type 2E (20, 21). A relationship between the NEFL gene and hypertension has not been reported, but we could not exclude the possibility that the observed relations were due to linkage of the LPL gene or the NEFL gene polymorphic markers to another gene that directly affects BP. In this region, the $\alpha-1 \mathrm{C}$ adrenergic receptor gene, closely linked to the NEFL gene and physiologically related to regulation of BP in human beings, might be responsible for association with hypertension (7).

In a 20-cM region defined by markers D8S511, D8S1145, D8S261, D8S258, D8S282, D8S560, and NEFL on chromosome 8 , which maps between 29.5 to $50.0 \mathrm{cM}$ from the $8 \mathrm{p}$ - telomere contained LPL gene, three markers demonstrated evidence for linkage with hypertension, D8S511 (9.5 cM telomeric to the LPL gene, $p=0.0036)$, D8S1145 (8 cM telomeric to the LPL gene, $p=0.0286)$ and D8S560 $(3.2 \mathrm{cM}$ centromeric to the LPL gene, $p=0.0115)$. Furthermore, TDT/S-TDT tests provided evidence for linkage-disequilibrium of the marker D8S261 with hypertension. It was postulated that chromosome region $8 \mathrm{p} 22$ might harbor some genes associated with hypertension apart from the LPL gene.

In conclusion, our results identified a $20-\mathrm{cM}$ region of human chromosome 8 that flanks the LPL gene and that showed evidence of linkage and association with BP or hypertension in Chinese population. Further studies using single nucleotide polymorphism (SNP) markers in and around the LPL and other candidate genes in the identified region are needed to confirm these results.

\section{References}

1. Sass C, Herbeth B, Siest G, Visvikis S: Lipoprotein lipase $(\mathrm{C} / \mathrm{G})^{447}$ polymorphism and blood pressure in the Stanislas cohort. J Hypertens 2000; 18: 1775-1781.

2. Pan WH, Chen JW, Fann C, Jou YS, Wu SY: Linkage analysis with candidate genes: the Taiwan young-onset hypertension genetic study. Hum Genet 2000; 107: 210-215.

3. Razzaghi H, Aston CE, Hamman RF, Kamboh MI: Genetic screening of the lipoprotein lipase gene for mutations associated with high triglyceride/low HDL-cholesterol levels. Hum Genet 2000; 107: 256-267.

4. Humphries SE, Nicaud V, Margalef J, Tiret L, Talmud PJ: Lipoprotein lipase gene variation is associated with a paternal history of premature coronary artery disease and fasting and postprandial plasma triglycerides: the European atherosclerosis research study (EARS). Arterioscler Thromb Vasc Biol 1998; 18: 526-534.

5. Shimo-Nakanishi Y, Urabe T, Hattori N, et al: Polymorphism of the lipoprotein lipase gene and risk of atherothrombotic cerebral infarction in the Japanese. Stroke 2001; 32: $1481-1486$.

6. Klannemark M, Suurinkeroinen L, Orho-Melander M, Groop L, Taskinen MR: Interaction between the Asn 291 Ser variant of the LPL gene and insulin resistance on dyslipidaemia in high risk individuals for type 2 diabetes mellitus. Diabet Med 2000; 17: 599-605.

7. Wu DA, Bu XD, Warden $\mathrm{CH}$, et al: Quantitative trait locus mapping of human blood pressure to a genetic region at or near the lipoprotein lipase gene locus on chromosome 8p22. J Clin Invest 1996; 97: 2111-2118.

8. Chu S, Zhu D, Xiong M, Wang GL, Jin L: Linkage analysis of candidate genes for glucose and lipid metabolism with essential hypertension. Natl Med J China 2001; 81: 20-22.

9. S.A.G.E. Statistical Analysis for Genetic Epidemiology, Release 2.1. Computer Program Package Available from the Department of Biometry and Genetics. New Orleans, Louisiana State University Medical Center, 1992.

10. Spielman RS, Ewens WJ: A sibship test for linkage in the presence of association: the sib transmission/disequilibrium test. Am J Hum Genet 1998; 62: 450-458. 
11. Fornage M, Amos CI, Kardia S, Sing CF, Turner ST, Boerwinkle E: Variation in the region of the angiotensin-converting enzyme gene influences interindividual differences in blood pressure levels in young white males. Circulation 1998; 97: 1773-1779.

12. Lifton RP, Gharavi AG, Geller DS: Molecular mechanisms of human hypertension. Cell 2001; 104: 545-556.

13. Kato N: Genetic analysis in human hypertension. Hypertens Res 2002; 25: 319-327.

14. Wu KD, Hsiao CF, Ho LT, et al: Clustering and heritability of insulin resistance in Chinese and Japanese hypertensive families: a Stanford-Asian Pacific Program in hypertension and insulin resistance sibling study. Hypertens Res 2002; 25: 529-536.

15. Doris PA: Hypertension genetics, single nucleotide polymorphisms, and the common disease: common variant hypothesis. Hypertension 2002; 39: 323-331.

16. Mingorne G, Henrihsen FL, Greco AV, et al: Triglycerideinduced diabetes associated with familial lipoprotein lipase deficiency. Diabetes 1999; 48: 1258-1263.

17. Hunt SC, Province MA, Atwood LD, et al: No linkage of the lipoprotein lipase locus to hypertension in Caucasians. $J$ Hypertens 1999; 17: 39-43.

18. Levy D, DeStefano AL, Larson MG, et al: Evidence for a gene influencing blood pressure on chromosome 17: genome scan linkage results for longitudinal blood pressure phenotypes in subjects from the Framingham heart study. Hypertension 2000; 36: 477-483.

19. Mattu RK, Needham EWA, Morgan R, et al: DNA variants at the LPL gene locus associate with angiographically defined severity of atherosclerosis and serum lipoprotein levels in a Welsh population. Arterioscler Thromb 1994; 14: 1090-1097.

20. Seitz S, Werner S, Fischer J, Nothnagel A, Schlag PM, Scherneck S: Refined deletion mapping in sporadic breast cancer at chromosomal region 8p12-p21 and association with clinicopathological parameters. Eur J Cancer 2000; 36: $1507-1513$.

21. De Jonghe P, Mersivanova I, Nelis E, et al: Further evidence that neurofilament light chain gene mutations can cause Charcot-Marie-Tooth disease type 2E. Ann Neurol 2001; 49: 245-249. 